\title{
Population indices measuring health outcomes: A scoping review
}

\author{
Khalid Ashraf', Chirk Jenn Ng' \\ Chin Hai Teo ${ }^{1}$, Kim Leng Goh² \\ ${ }^{1}$ Department of Primary Care Medicine, \\ Faculty of Medicine, University of Malaya, \\ Kuala Lumpur, Malaysia \\ ${ }^{2}$ Department of Applied Statistics, Faculty \\ of Economics and Administration, \\ University of Malaya, Kuala Lumpur, \\ Malaysia
}

Background Population health indices such as disability adjusted life years (DALY) and quality adjusted life years (QALY) are often used in an effort to measure health of populations and identify areas of concern that require interventions. There has been an increase of number of population health indices since the last review published more than a decade ago. Therefore, this study aims to provide an overview of existing population health indices and examine the methods used to develop them.

Methods The search was conducted across three databases: PubMed, CINAHL and Emerald using four key concepts: 'health', 'index', 'context', 'develop', which was supplemented with Google searching and reference scanning. A researcher screened the titles, abstracts and subsequently full texts and confirmed the findings with the research team at each stage. Data charting was performed according to the included publications and identified indices. The collation was performed by describing the indices and made observation on its development method using a priori framework consist of four processes: underpinning theory, model or framework; data selection and processing; formation of index; testing of index.

Results Twenty-six publications describing population health indices were included, and 27 indices were identified. These indices covered the following health topics: overall health outcomes $(n=15)$, outcomes for specific health topics $(n=4)$, diseases outcome $(n=6)$, assist health resource allocation for priority minority subgroup or geographic area $(n=4)$, quality of health or health care $(n=2)$. Twenty-one indices measure health for general populations while six measure defined subpopulations. Fourteen of the indices reported at least one of the development processes according to the a priori framework: underpinning theory, model or framework $(n=7)$; data selection and processing $(n=8)$; formation of index $(n=12)$; testing of index $(n=9)$.

Conclusions Few population health indices measure specific health topics or health of specific sub-population. There is also a lack of usage of theories, models or framework in developing these indices. Efforts to develop a guideline is proposed on how population health indices can be developed systematically and rigorously to ensure validity and comprehensive assessment of the indices.

Population health is a field of research that has been growing rapidly in recent years. Population health approach aims to improve health of the entire population and reduce health inequities within population. It is a broad field ranging from the study of diverse set of health outcomes and determinants to the discourse of health policy intervention [1]. Kingdon argued that the authorities attend to various problems at a time, and this in turn makes some problems prioritized and others ignored. He added, one of the facilitators that

\section{Correspondence to:}

Chirk Jenn Ng, MMed, PhD

Department of Primary Care Medicine

Faculty of Medicine, University of Malaya

Jalan Universiti, 50603 Kuala Lumpur

Malaysia

ngcj@um.edu.my 
captures the attention of the authorities are indicators, which are used in two major ways: to assess the magnitude of a problem and to become aware of changes in the problem [2]. In the context of health policy discourse, health indicators are excellent means of promoting statistical comparability within and among health care systems. Health indicators are statistics selected to represent relevant characteristics of population health because of their power to summarize, or to serve as indirect or proxy measures for information that is lacking [3].

In recent years, researchers have combined population health indicators into an index to gain a wider perspective for their study. An index is defined by the Organisation for Economic Co-operation and Development (OECD) as "a composite indicator that is formed when individual indicators are compiled into a single index, on the basis of an underlying model of the multi-dimensional concept that is being measured" [4]. A population health index therefore provides a summary measure of a certain health characteristic at the population level. For instance, disability adjusted life years (DALY), which combines number of years lost due to premature death and number of years lost due to disability burden, was developed as a measure of the burden of disease. DALY as a single unit enable a multidimensional assessment of health outcome to be considered in comparison with a unidimensional unit for resource allocation, in unit of dollar for example. It provides a comparable measure of output for the design of an intervention or programme for different health problems, which helps to shift the relative weight of political decisions to evidence-based decision making in health resource allocation [5].

There are many population indices that were developed around the globe. Bandura's survey listed 178 indices, while Yang's inventory captures 101 indices [6,7]. However, these compilations of population indices include topics beyond health. In addition, both did not use any systematic searching approach for their compilation. Hence, the comprehensiveness of the population indices listing is questionable. In 2004, Kaltenthaler et al published a systematic review to identify articles describing population health indices and their development [8]. This systematic review, which was published before the PRISMA statement [9], did not describe an explicit reproducible method [10], particularly a clearly defined eligibility criteria and search strategy. Nevertheless, Kaltenthaler et al argued that a review on population health indices is beneficial because indices may facilitate the consideration of allocating and targeting health resources based on health needs from a multidimensional perspective.

Given the range of methodological variants in developing an index [6-8], an overview of the methodological approaches is essential. This will benefit future researchers who have the intention to develop a new population health index and to assess the suitability of the chosen method.

It is timely to conduct another review on population health indices given that Kaltenthaler et al's systematic review was published more than a decade ago and we found no other systematic review conducted on population health indices since then. This study has two objectives, namely, (1) to provide an overview of existing population health indices in the literature, and (2) to examine the methods used to develop these population health indices.

\section{METHODS}

\section{Approach}

The scoping review methodology was chosen to identify the range of population health indices available from existing literature [11-14]. Arksey and O'Malley outlined five stages of a scoping review: identifying a research question; identifying relevant studies; selecting studies; charting the data; and collating, summarizing and reporting the results [11]. The exploratory nature of our research objective makes a systematic review method, which requires a focused question, not feasible; whereas, the breadth of a scoping review, which considers many different study designs to identify all relevant literature is more appropriate for this study $[11,15]$. After selecting the relevant studies, the population health indices identified were analysed to examine the methods used to develop these indices. The methodology paper by the Joanna Briggs Institute was used as a guide to conduct this scoping review [14]. Where appropriate, The Preferred Reporting Items for Systematic Reviews and Meta-Analyses (PRISMA) guided the reporting of this scoping review (Appendix A in Online Supplementary Document) [9].

\section{Eligibility criteria}

Publications selection were guided by the 'population', 'concept' and 'context' (PCC) elements which ensure the coverage of a broader scope of study designs with less restrictive criteria [14,16]. No imposi- 
tion was made for population criteria, since the objective of this scoping review is to give an overview of population health indices in general regardless of which population it focuses onto, for example, whether children or native population.

The first concept applied to guide the selection is 'index', where we used the concept of 'composite indicator' as defined by the OECD [4]. The second guiding concept is 'health', where the dimensions measured by the index are health outcomes, not a health determinant or a social determinant of health. Only publications with population health indices covering these two concepts are eligible for inclusion.

In the case of 'context', indices measuring a health concept at individual-level (eg, body mass index, patient satisfaction index, Cornell medical index) were excluded since the interest of this review is to search for population-level health indices. We decided not to use Kaltenthaler et al's criterion, which excluded indices that combined only one health indicator with other non-health indicators to form an index because the inclusion of one health indicator qualifies the index to be considered as a health index. This criterion used in Kaltenthaler et al ended up excluding quality-adjusted life years (QALY), which, in our opinion, is important to be included because of its widespread use in population health measurement $[17,18]$. This scoping review did not limit to just original research journal articles but also included reports and journal review articles. No publication date or publication status restrictions were imposed. Only English language publications were considered.

\section{Scoping for population health indices}

Publications were first identified by searching electronic databases. The search was applied to two biomedical databases (PubMed on 3rd March 2016 and CINAHL on 10th March 2016) and one multidisciplinary database (Emerald on 10th March 2016). The search strategy (Appendix S2 in Online Supplementary Document) was developed together by KA, CHT and CJN. We have combined the concept of 'develop' with 'health', 'index' and 'context' to narrow down to publications that also discussed the development process of their health indices. Supplementary search was conducted on $19^{\text {th }}$ May 2016 using Google search engine. All searches were conducted by KA with guidance from CJN. Bibliographic management software, EndNote X7, was used to import and manage the publications. The reference lists of the included publications were also scanned to further identify relevant publications.

\section{Screening publications}

First, the publications identified were screened on the basis of title and abstract. We subsequently retrieved the full-text of the relevant publications to further assess their eligibility. The reference lists of all the eligible publications were examined to look for additional eligible publications. The screening process was conducted by KA and cross-checked with CJN and CHT regularly in batches.

\section{Charting the data}

Data charting was conducted in two phases: (1) the included publications, and (2) the population health indices identified from the included publications. We developed a data charting map (Appendix C in Online Supplementary Document) according to the two objectives of this study to guide the charting process. The data charting map was pilot tested on seven randomly selected included publications, and refined accordingly.

\section{Collating}

The collation was conducted in two parts. First, we sorted the identified population health indices according to the year they first appeared in the included publications. Brief description of the indices was made about its purpose, data, target population, metric and application. We further organized the indices into several categories based on the description made.

The second part observed the development process of these indices. We developed a priori analytical framework, which was adapted from the OECD's 'Handbook on Constructing Composite Indicators' [19]. The simplified framework consists of four processes: (1) underpinning theory, model or framework; (2) data selection and processing; (3) formation of index; and (4) testing of index. All identified indices were mapped against these four processes of development. 


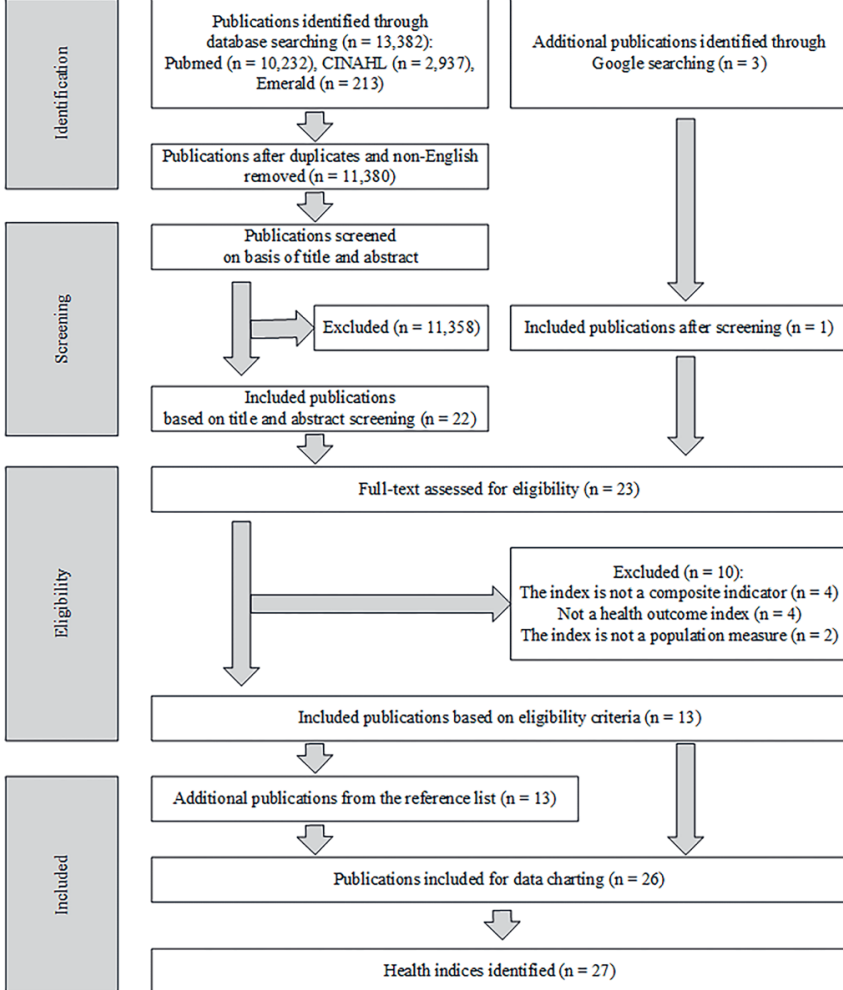

Figure 1. PRISMA flow diagram.

\section{RESULTS}

\section{Search results}

The electronic database search retrieved 13382 publications (Figure 1). Twenty-six publications were included after screening through titles, abstracts and full texts.

\section{Characteristics of included publications and identified population health indices}

Out of the 26 included publications, most were published as original research articles (65\%) and half were published before year 2000. Twenty-seven population health indices were identified from the included publications (Table 1). The population health indices varied in their nomenclature; 'index' was the term most used $(n=16)$, followed by 'indicator' $(n=6)[24,33,45]$, 'measure' $(n=2)$ $[29,34]$, 'composite indicator' $(n=2)$ [37], 'composite in$\operatorname{dex}(n=2)[38,40]$, and 'ranking' $(n=1)$ [44].

\section{Index topics}

Fifteen of the indices measure overall health outcomes (eg, Chiang's H index, gross national health product) $[8,20,22,24,30,33,36,38,44,46]$, four indices measure specific health outcomes (eg, undernourishment [40], nutrition [42], inequality of mortality [45], and inequality of health outcomes based on Millennium Development Goals [43]) and six indices measure population health based on disease-specific outcome (eg, Miller's Q index, Chen's G index) [21,29,31,34]. Two indices focused on the topic of quality: 'K index' on the quality of health care [28], and 'quality-adjusted life years' on quality of health [28,29]. Four indices were developed as a measure to assist decision making in health resource allocation (eg, Canadian Indian health status index, general index of health) [21,31,32].

\section{Target population}

Twenty-one of the population health indices measure health for general populations; three measure hypothetical populations $[20,28,29]$, while the other 18 measure real populations $[8,22,24,30,32-34,37,42$ 46]. Thirteen indices cover country-level populations $[22,24,30,33,34,37,42,43,45,46]$, while five indices cover smaller areas (ie, electoral wards, districts and counties) $[8,32,44]$. The remaining six indices measure defined subpopulations; three cover children $[36,38,40]$, and another three indices target specific ethnic or native population [21,31].

\section{Index data}

Out of 27 population health indices, all used mortality data except one (composite index of anthropometric failure [40]). Five of the indices coupled mortality data together with birth data $[8,32,36,38]$. Morbidity data were used in two ways to represent health status: (1) using disability or handicap data in general [8,20,21,24,28,30]; (2) using disease-specific morbidity data [24,34,37,40,42,43]. Other categories of indices include: five indices used data of health care service delivery or intervention $[21,29,31,43]$; five used physical well-being data $[8,24,29,44]$; index of multiple deprivation used welfare data to form the index [8]; nine indices used general population characteristics (eg, population size by age group) and life expectancy data $[22,24,30,33,42,46]$.

\section{Development processes}

Fourteen population health indices reported at least one of the development processes in the simplified framework (Table 2). Seven indices reported use of a theory, model or framework to provide a basis for combining individual indicators into a meaningful index [36,37,40,42-45]. Only eight indices explained how the data was chosen or processed $[30,36,38,40,42,43,45,46]$. Twelve indices reported the methods used to form the index $[8,21,30,32,33,36-38,40,42,43,45]$. Only nine indices were tested statistically after they were formed $[21,33,36-38,40,42,43,46]$. 


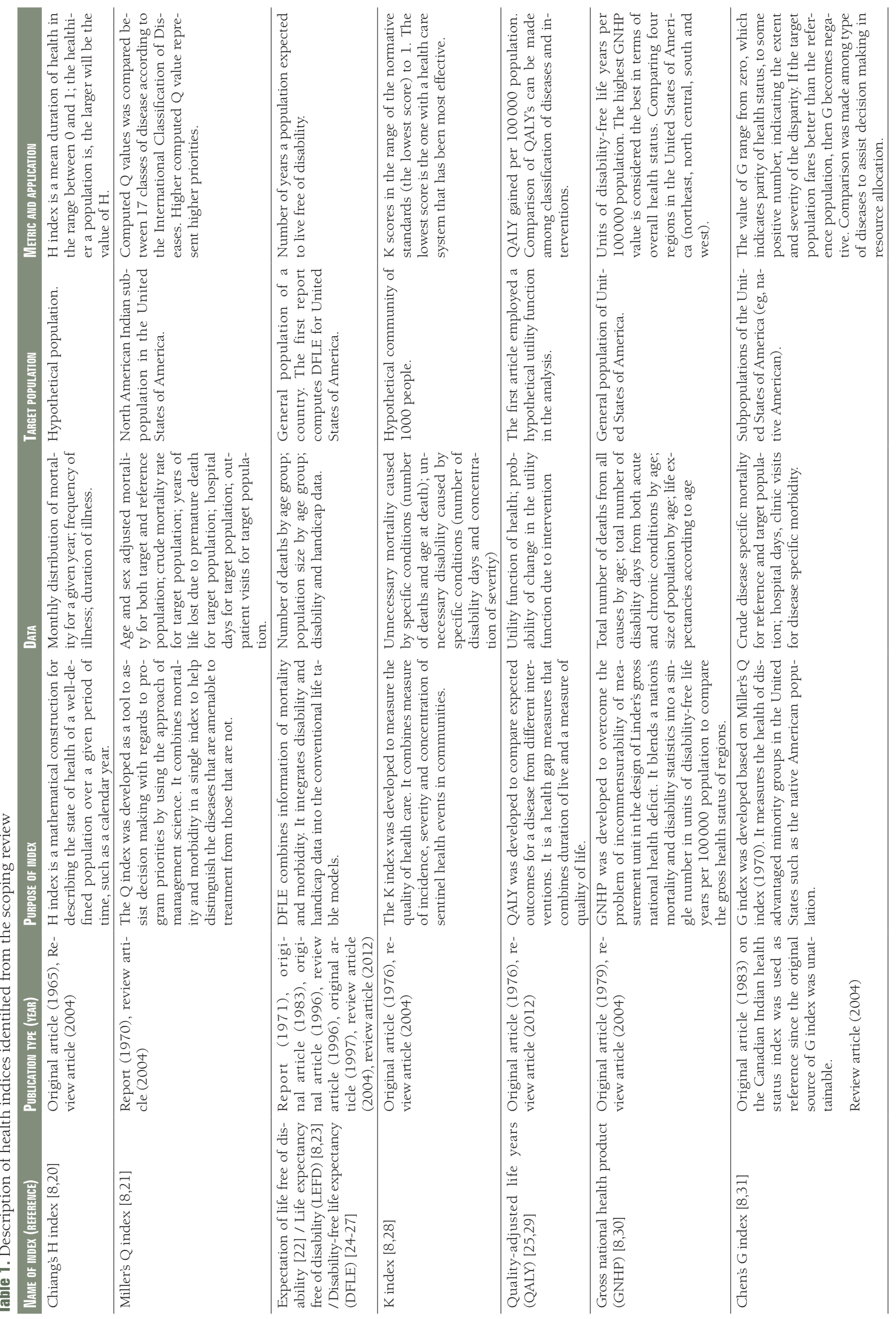




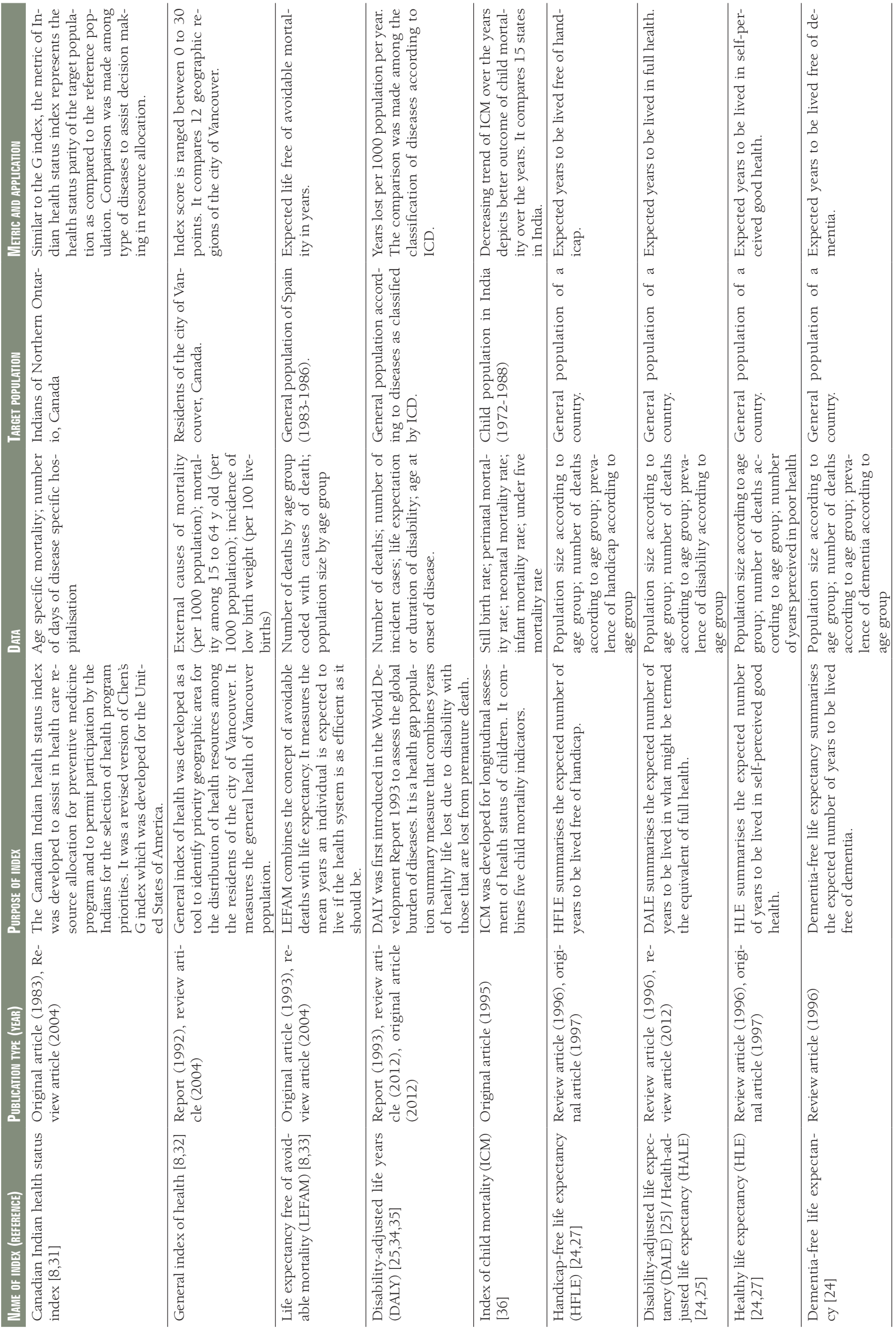




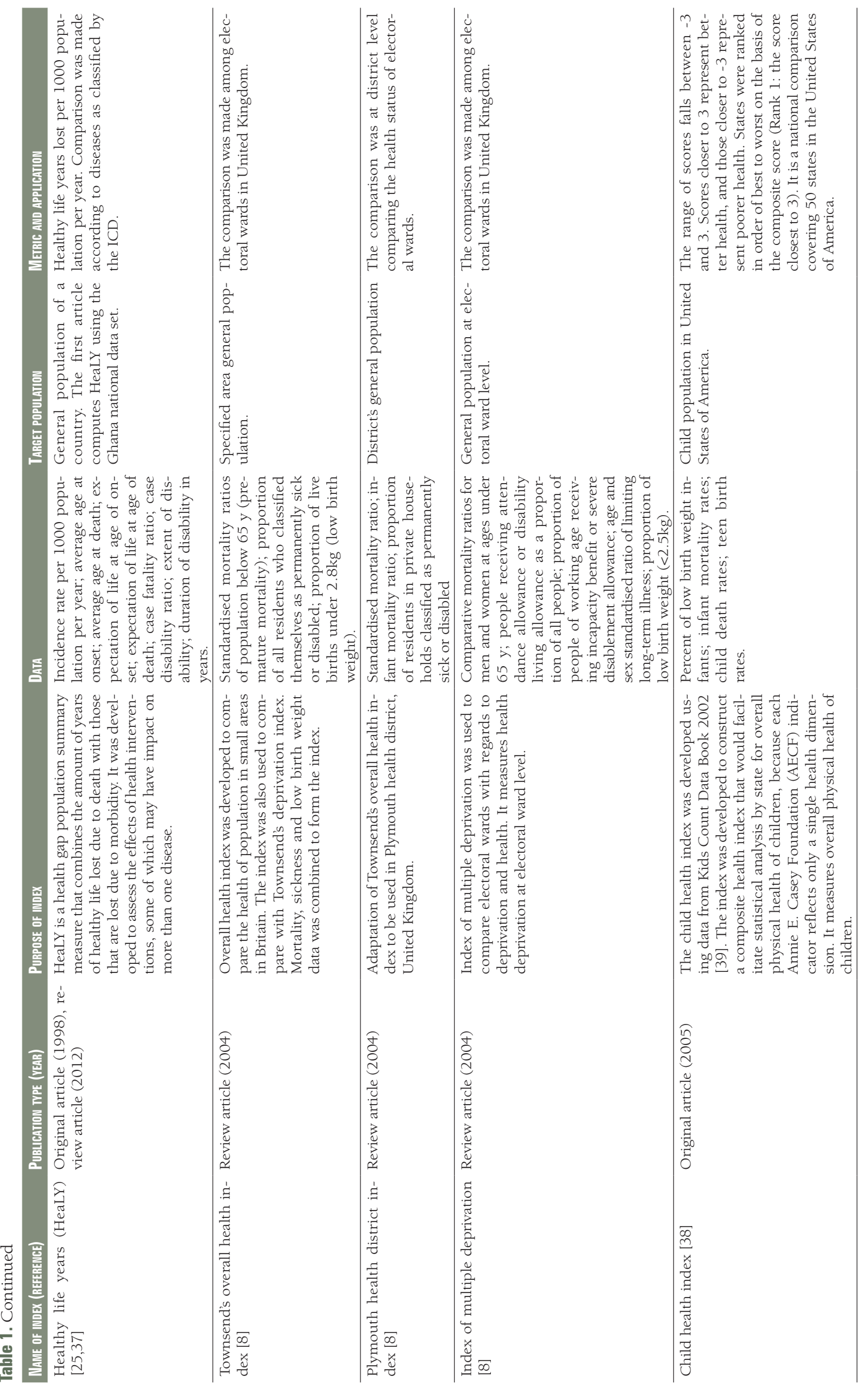




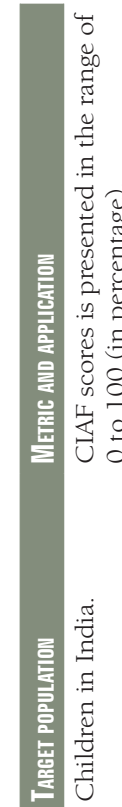

000

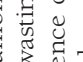

$20 \frac{1}{3} \frac{\pi}{3}$

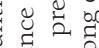

政

递苛

वृ $\tilde{\Phi}_{\text {in }}$

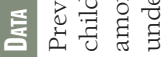

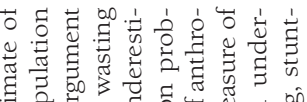

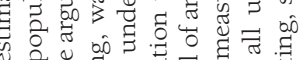

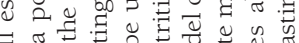

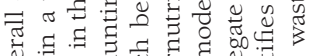

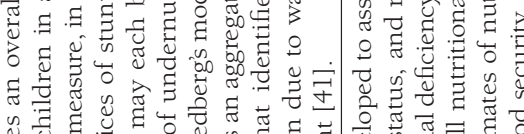

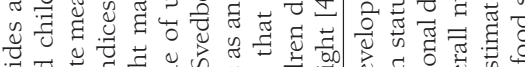

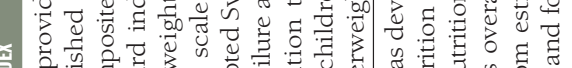
学

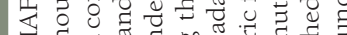
尊

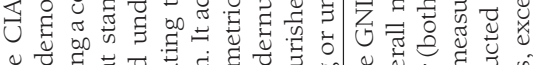

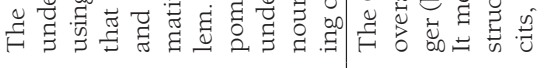

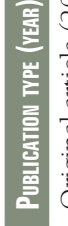

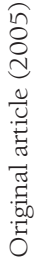

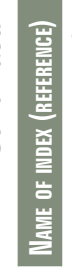

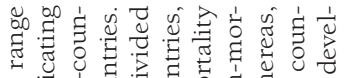

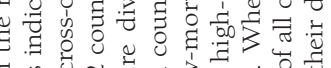

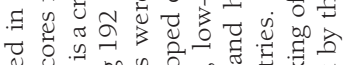

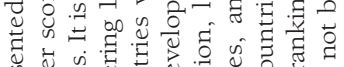

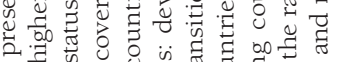

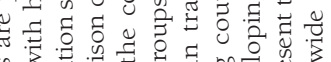

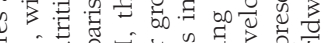

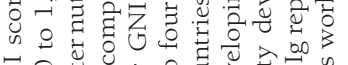

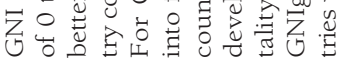

$\pi$
+0
0
0
$\frac{\pi}{3}$
0
0

苞

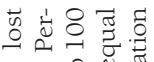

is is i :

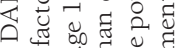

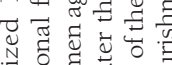

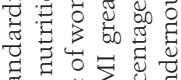

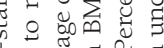

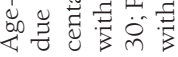

记实苟它它

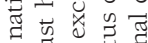

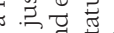

के क्ष के

尊记

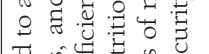

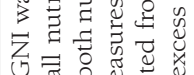

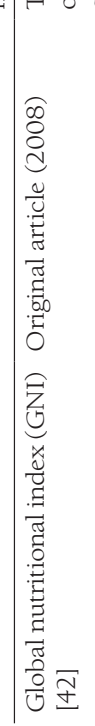

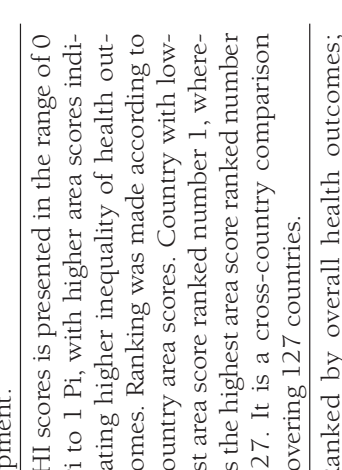

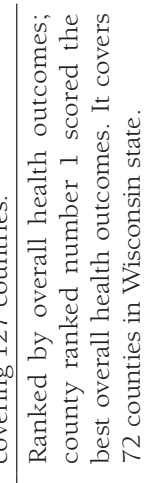

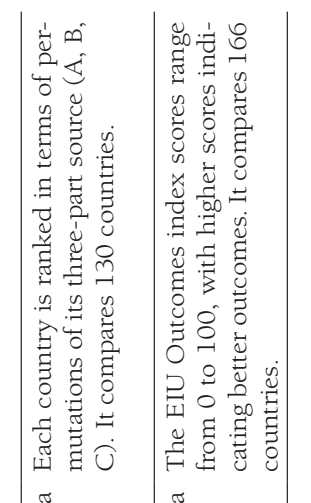

๘

范

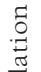

$\frac{\pi}{3}$
$\frac{\pi}{2}$
$\stackrel{2}{2}$

苞富

نั

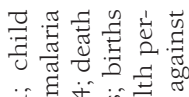

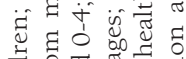

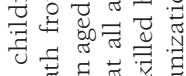

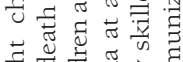

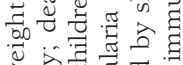

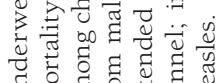

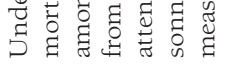

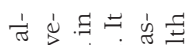

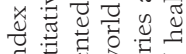

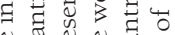

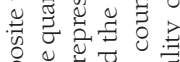

羊告

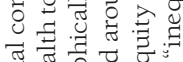

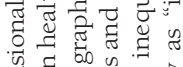

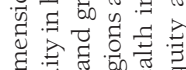

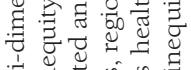

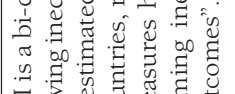

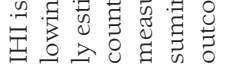

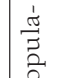

ฉิ

苞

苞

党

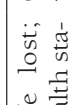

$\cong$ 苞

要

․․

䒘莒

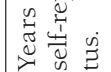

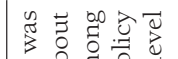

类

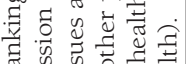

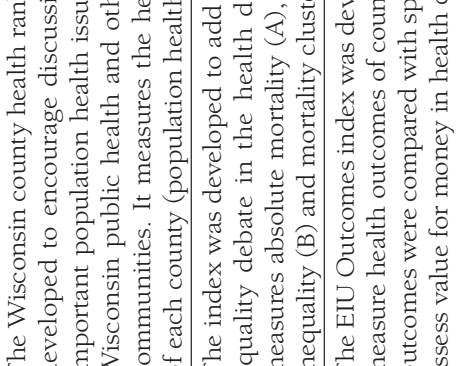

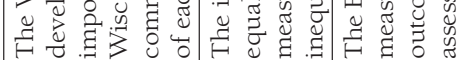

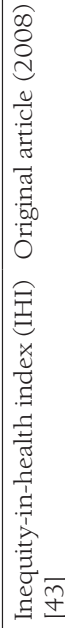

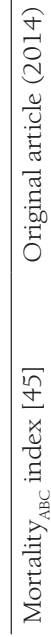

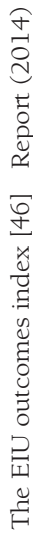

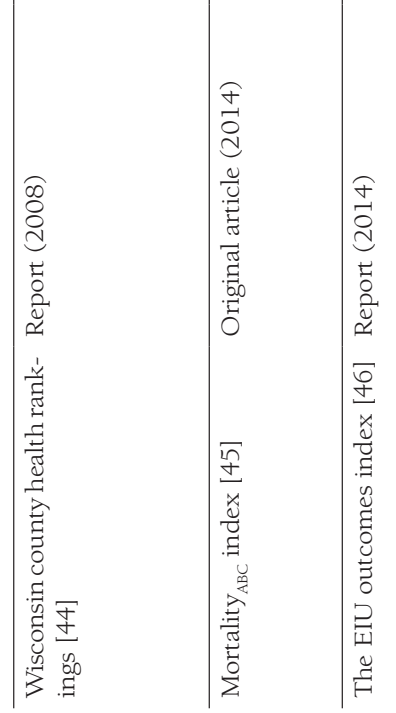




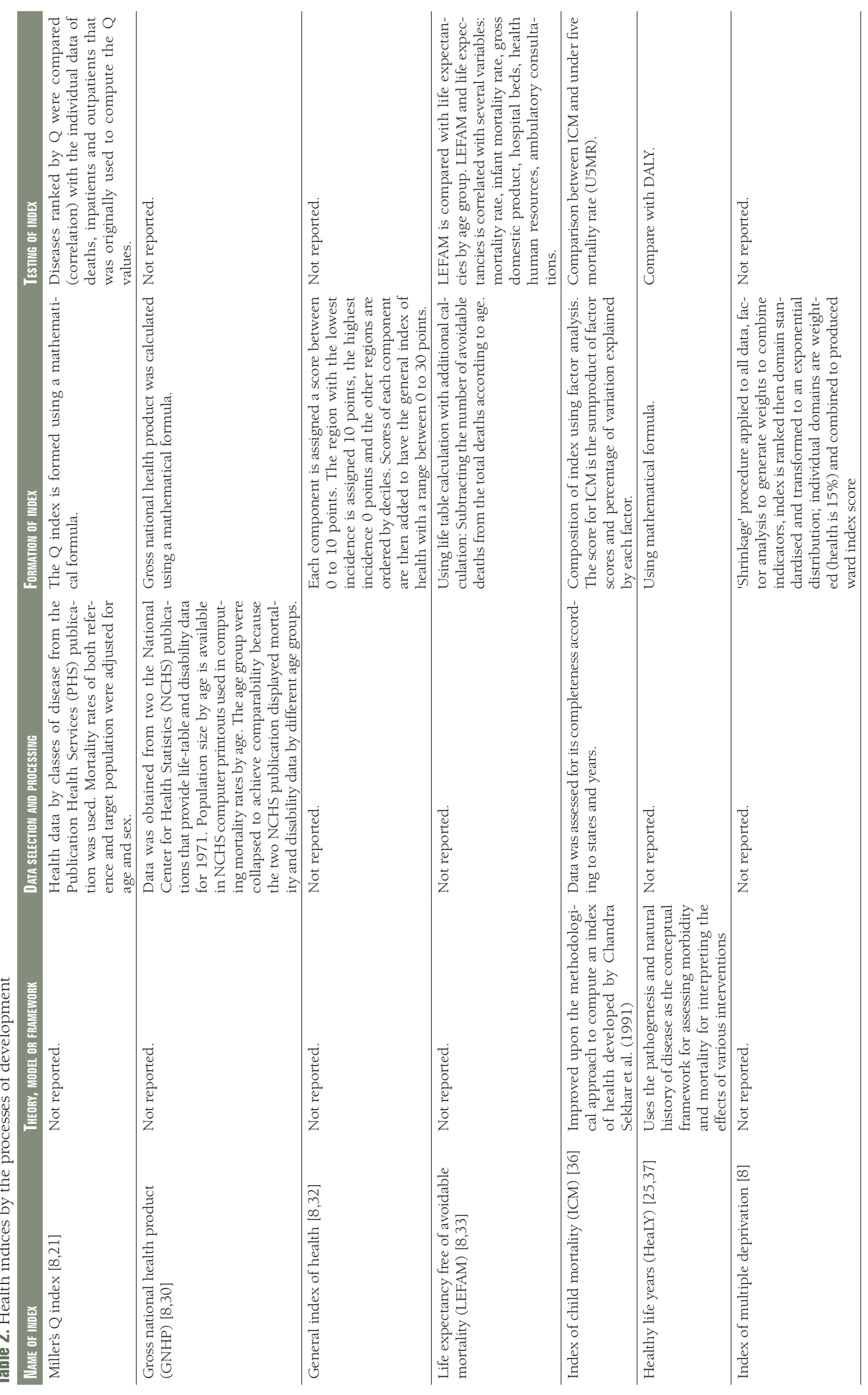




\begin{tabular}{|c|c|c|c|c|}
\hline 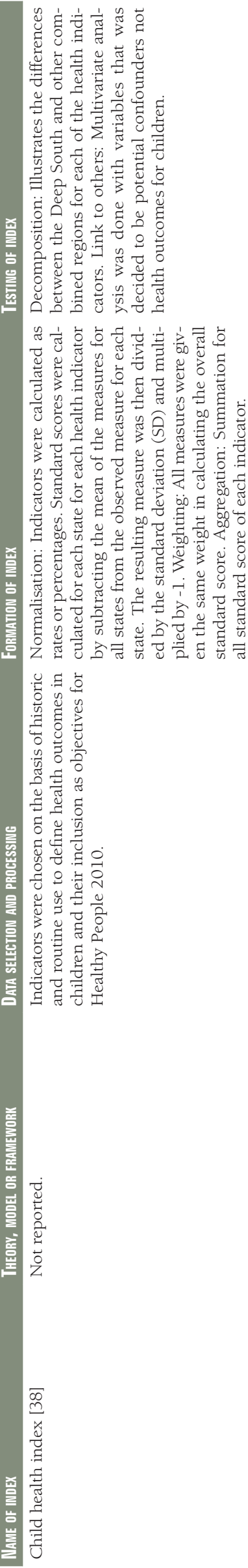 & 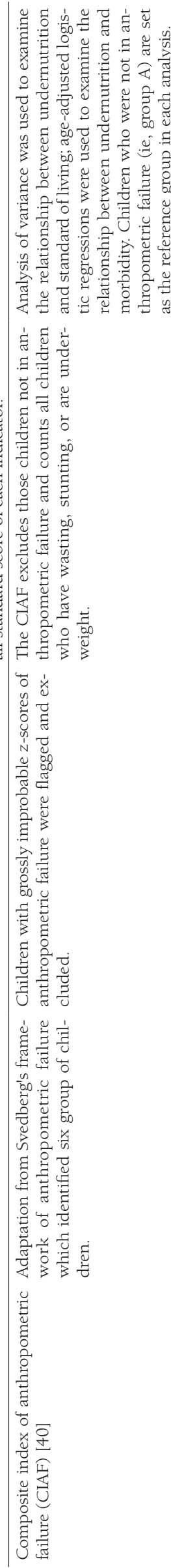 & 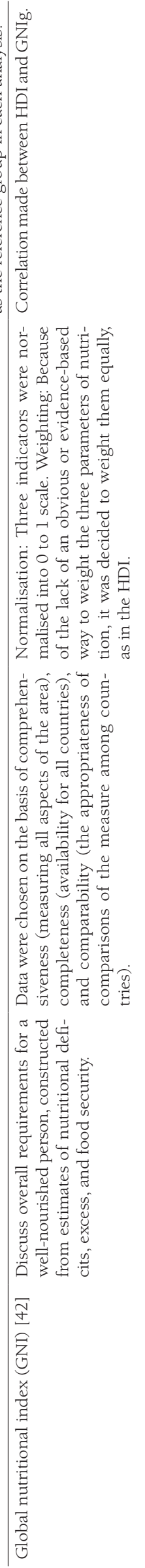 & 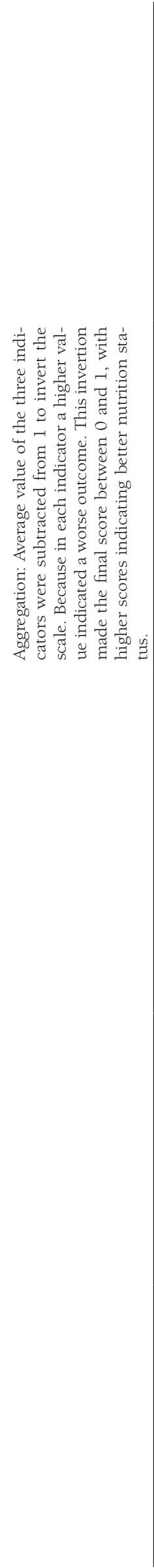 & 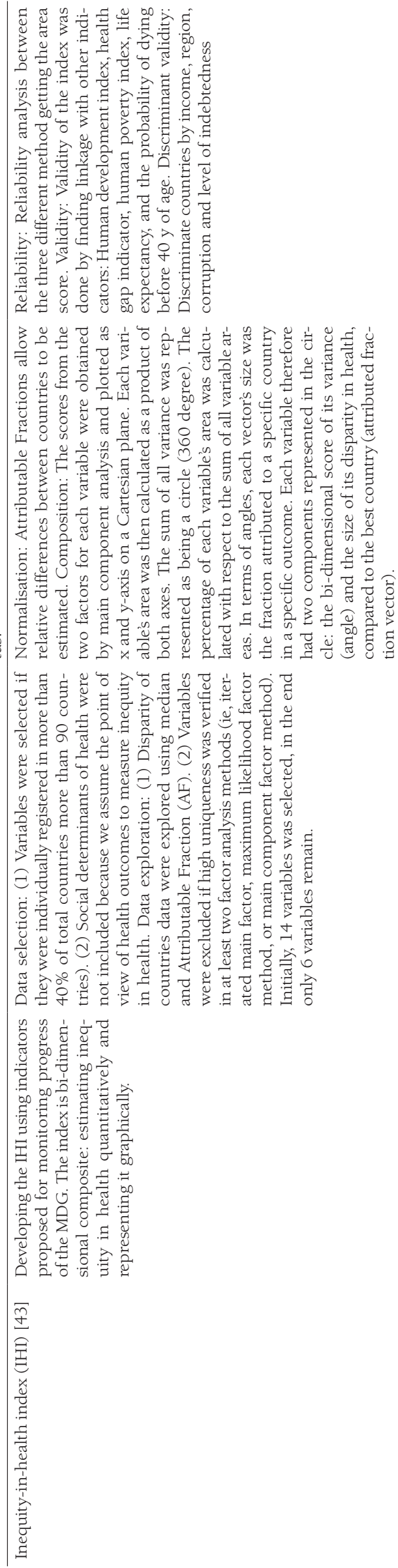 \\
\hline
\end{tabular}




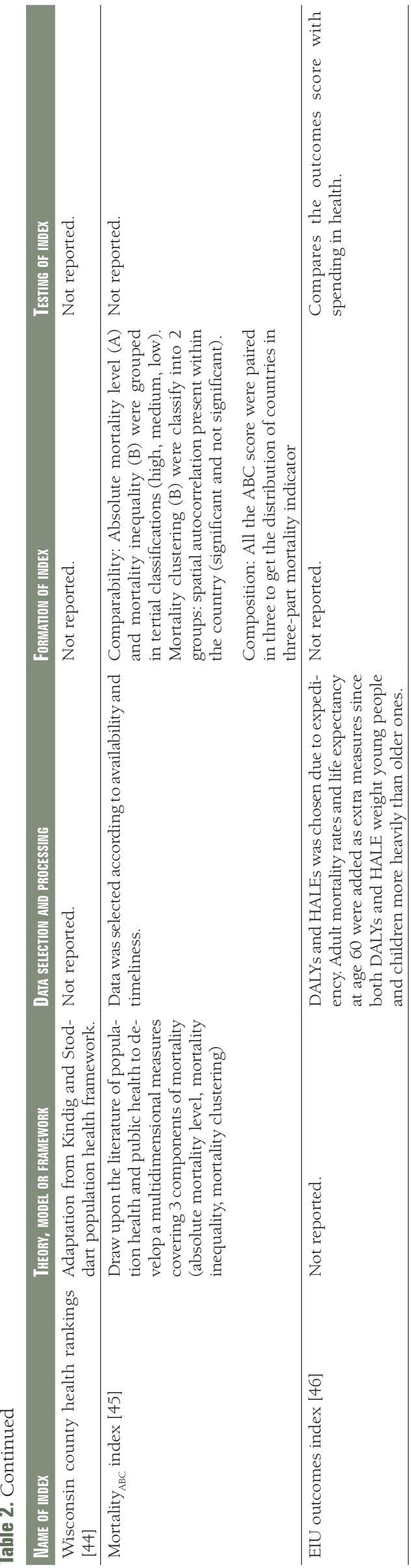

\section{DISCUSSION}

This scoping review provides an updated overview of existing population health indices in the literature and examines systematically the methods used in developing these indices. Existing reviews mainly cover indices that originated from prominent international organizations. Van de Water et al produced an inventory of indices that originated from European Union member states [24], while Hyder et al presented a narrative review of indices that originated from the World Bank and the World Health Organization [25]. Our review, which also covers indices that were born out of research practice, revisits Kalthenthaler et al.'s attempt in conducting a systematic search of published indices in the literature. The method we used included 26 publications and identified 27 health indices documented in the period that spans 50 years (1965-2014).

The included population health indices highlights that most health indices focus on a population's overall health outcomes, or the health of a general population. Measuring health with a more focused purpose or on a specific subpopulation allows for specific policy or intervention to be developed and implemented. For instance, the composite index of anthropometric failure (CIAF) estimates the number of undernourished children in a population. It demonstrates that the prevalence of undernutrition among children in India was greatly underestimated by the using standard indicators of stunting, wasting or underweight [40]. Global nutritional index (GNI) highlights the trade-off between the problem of undernutrition and obesity at a global scale that may assist policy decision making in global nutrition aid [42]. This scoping review only managed to identify three indices that measure outcomes of children's health and another three that measure the health outcomes of specific ethnic or native population. Similarly, women's health issues have received relatively more social interest compared to men's health issues, despite data have been showing men are faring worse in various aspects of health $[47,48]$. A population index that measures various outcomes of men's health in a single index, and allows for cross-country comparison, may provide the needed exposure of this problem more strategically.

The usage of a theory, model or framework as the basis to develop measures of health outcomes is lacking but necessary [49]. It helps readers to understand better by providing the context into the multidimensional concept of the index. It identifies whether the indicators used is a measure of health outcomes or health determinants, and provides insight into the relationships between indicators. The inclusion of a theory, model or framework will ensure a population health index is not merely a statistical amalgamation of indicators but also founded on valid health concepts.

\section{Limitations}

Our search identified 13 publications from the eligibility criteria. The search is ostensibly narrow, but the outcome is due to two concepts that we used in our search strategy: 'INDEX' and 'DEVELOP' (Appendix B in Online Supplementary Document). Publications that defined their population health measure as 'INDICATOR' are omitted in our initial search since indicators are components of an index, and they do not present the full reflection expected of an index. Since our second objective is to examine the methods used to develop these population health indices, 'DEVELOP' was included 
as a concept in the search. Publications on population health indices with titles and abstracts that do not fulfil this concept are further excluded in the initial search.

A supplementary search using Google search engine was conducted. However, specific website search, for instance search on population health indices in the websites of relevant government departments, was not conducted.

Our review also did not use the Peer Review of Electronic Search Strategies (PRESS) to help guide and improve the peer review of our electronic search strategies, as PRESS was published after the completion of the search.

Although scoping review methodology does not require appraisal of the study [11-13,50], a quality assessment of population health indices is important. Currently there is no guideline to allow critical comparisons of existing indices. Development of such a guideline will enable comprehensive assessment of the quality of health indices which is essential to advance the methodological discourse for developing population indices in health research.

Our review only includes indices that measure a multidimensional health outcome. This review excluded indices that measure solely determinants of health (eg, Urban Health Index) or well-being of a population (eg, Human Development Index, OECD Better Life Index). Future reviews may want to include other indices that cover non-health outcomes.

\section{CONCLUSION}

Even after 50 years of ongoing usage of population health indices, knowledge in this area are rarely discussed in academic literature. This scoping review highlights two important gaps. First, most of the population health indices measure a population's overall health outcomes, but only few gave focus to specific health topics or health of specific sub-populations. Second, there is a lack in the usage of theory, model or framework as a basis to develop health concept measurement. This process is important as it ensures the overall validity of the developed population health index. A more in-depth analysis of population health indices is required so that methodological developments and refinements are continuous in this area of knowledge. It is necessary to develop a guideline on how population health indices can be developed systematically and rigorously.

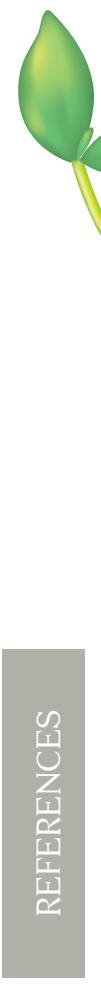

Funding: This study was supported by the University of Malaya Research Programme (Project code: RP041D15HTM).

Authorship declaration: The search strategy was developed together by KA, CHT and CJN. KA undertook all the searches with guidance from CHT and CJN. KA charted publications data and reviewed by CJN and KLG. KA wrote the first draft of the manuscript and all authors contributed to further drafts and preparing the article for publication.

Competing interests: The authors have completed the Unified Competing Interest form at www.icmje.org/coi_ disclosure.pdf (available on request from the corresponding author) and declare no conflict of interest.

Additional Material

Online Supplementary Document

1 Kindig D, Stoddart G. What is population health? Am J Public Health. 2003;93:380-3. Medline:12604476 doi:10.2105/ AJPH.93.3.380

2 Kingdon JW. Agendas, Alternatives, and Public Policies. 2nd ed. New York: HarperCollins College Publishers; 1995.

3 Murnaghan JH. Health indicators and information systems for the year 2000. Annu Rev Public Health. 1981;2:299-361. Medline:7348555 doi:10.1146/annurev.pu.02.050181.001503

4 OECD. Composite Indicator. 2004. Available: http://stats.oecd.org/glossary/detail.asp?ID=6278. Accessed: 1 November 2018.

5 Murray CJ. Quantifying the burden of disease: the technical basis for disability-adjusted life years. Bull World Health Organ. 1994;72:429-45. Medline:8062401 
6 Bandura R. A survey of composite indices measuring country performance: 2008 update. Office of Development Studies, New York: United Nations Development Programme. 2008.

7 Yang L. An inventory of composite measures of human progress. Occasional Paper on Methodology. 2014.

8 Kaltenthaler E, Maheswaran R, Beverley C .Population-based health indexes: a systematic review. Health Policy. 2004;68:245-55. Medline:15063023 doi:10.1016/j.healthpol.2003.10.005

9 Moher D, Liberati A, Tetzlaff J, Altman DG. Preferred reporting items for systematic reviews and meta-analyses: the PRISMA statement. PLoS Med. 2009;6:e1000097. Medline:19621072 doi:10.1371/journal.pmed.1000097

10 Liberati A, Altman DG, Tetzlaff J, Mulrow C, Gotzsche PC, Ioannidis JP, et al. The PRISMA statement for reporting systematic reviews and meta-analyses of studies that evaluate healthcare interventions: explanation and elaboration. BMJ. 2009;339:b2700. Medline:19622552 doi:10.1136/bmj.b2700

11 Arksey H, O’Malley L. Scoping studies: towards a methodological framework. Int J Soc Res Methodol. 2005;8:19-32. doi:10.1080/1364557032000119616

12 Levac D, Colquhoun H, O’Brien KK. Scoping studies: advancing the methodology. Implement Sci. 2010;5:69. Medline:20854677 doi:10.1186/1748-5908-5-69

13 Daudt HM, Van Mossel C, Scott SJ. Enhancing the scoping study methodology: a large, inter-professional team's experience with Arksey and O'Malley's framework. BMC Med Res Methodol. 2013;13:48. Medline:23522333 doi:10.1186/14712288-13-48

14 Peters MD, Godfrey CM, Khalil H, McInerney P, Parker D, Soares CB. Guidance for conducting systematic scoping reviews. Int J Evid-Based Healthc. 2015;13:141-6. Medline:26134548 doi:10.1097/XEB.0000000000000050

15 Brien SE, Lorenzetti DL, Lewis S, Kennedy J, Ghali WA. Overview of a formal scoping review on health system report cards. Implement Sci. 2010;5:2. Medline:20205791 doi:10.1186/1748-5908-5-2

16 Peters M, Godfrey C, McInerney P, Soares C, Khalil H, Parker D. Methodology for JBI scoping reviews. 2015.

17 Rasanen P, Roine E, Sintonen H, Semberg-Konttinen V, Ryynanen OP, Roine R. Use of quality-adjusted life years for the estimation of effectiveness of health care: A systematic literature review. Int J Technol Assess Health Care. 2006;22:23541. Medline:16571199 doi:10.1017/S0266462306051051

18 Whitehead SJ, Ali S. Health outcomes in economic evaluation: the QALY and utilities. Br Med Bull. 2010;96:5-21. Medline:21037243 doi:10.1093/bmb/ldq033

19 Commission JRC-E. Handbook on constructing composite indicators: Methodology and User guide: OECD publishing; 2008.

20 Chiang CL. An Index of Health: Mathematical Models. Vital Health Stat 1. 1965;(3):1-19. Medline:14303186

21 Miller JE. An indicator to aid management in assigning program priorities. Public Health Rep. 1970;85:725-31. Medline:4988674 doi: $10.2307 / 4593948$

22 Sullivan DF. A single index of mortality and morbidity. HSMHA Health Rep. 1971;86:347-54. Medline:5554262 doi:10.2307/4594169

23 Colvez A, Blanchet M. Potential gains in life expectancy free of disability: a tool for health planning. Int J Epidemiol. 1983;12:224-9. Medline:6223894 doi:10.1093/ije/12.2.224

24 van de Water HP, Perenboom RJ, Boshuizen HC. Policy relevance of the health expectancy indicator; an inventory in European Union countries. Health Policy. 1996;36:117-29. Medline:10172658 doi:10.1016/0168-8510(95)00803-9

25 Hyder AA, Puvanachandra P, Morrow RH. Measuring the health of populations: explaining composite indicators. J Public Health Res. 2012;1:222-8. Medline:25170468 doi:10.4081/jphr.2012.e35

26 Mathers C. Trends in health expectancies in Australia 1981-1993. J Aust Popul Assoc. 1996;13:1-15. Medline:12321982

27 Mutafova M, van de Water HP, Perenboom RJ, Boshuizen HC, Maleshkov C. Health expectancy calculations: a novel approach to studying population health in Bulgaria. Bull World Health Organ. 1997;75:147-53. Medline:9185367

28 Chen MK. The K index: a proxy measure of health care quality. Health Serv Res. 1976;11:452-63. Medline:1030698

29 Zeckhauser R, Shepard D. Where Now for Saving Lives? Law Contemp Probl. 1976;40:5-45. doi:10.2307/1191310

30 Chen MK. The gross national health product: a proposed population health index. Public Health Rep. 1979;94:119-23. Medline:432403

31 Connop PJ. A Canadian Indian Health Status Index. Med Care. 1983;21:67-81. Medline:6601223 doi:10.1097/00005650198301000-00005

32 Rumel D, Costanzo G. The General Index of Health. Can J Public Health. 1992;83:82-3. Medline:1571892

33 Alfonso Sanchez J, Noguera BS, Delbano MJP, Pons AS, Sanchez CS, Greus PC. Testing a New Health Indicator - Using Avoidable Causes of Death and Life Expectancy for Spain between 1975-1986. Eur J Epidemiol. 1993;9:33-9. Medline:8472799 doi:10.1007/BF00463087

34 World Development Report 1993: Investing in Health. New York: World Bank, 1993.

35 Soerjomataram I, Lortet-Tieulent J, Ferlay J, Forman D, Mathers C, Parkin DM, et al. Estimating and validating disability-adjusted life years at the global level: a methodological framework for cancer. BMC Med Res Methodol. 2012;12:125. Medline:22901001 doi:10.1186/1471-2288-12-125

36 Satyanarayana L, Indrayan A, Sachdev HP, Gupta SM. A comprehensive index for longitudinal monitoring of child health status. Indian Pediatr. 1995;32:443-52. Medline:8635808

37 Hyder AA, Rotllant G, Morrow RH. Measuring the burden of disease: healthy life-years. Am J Public Health. 1998;88:196202. Medline:9491007 doi:10.2105/AJPH.88.2.196

38 Goldhagen J, Remo R, Bryant T III, Wludyka P, Dailey A, Wood D, et al. The health status of southern children: a neglected regional disparity. Pediatrics. 2005;116:e746-53. Medline:16263972 doi:10.1542/peds.2005-0366 
39 Annie E. Casey Foundation. 2002 Kids Count Data Book: State Profiles of Well-Being. Baltimore, MD: Annie E. Casey Foundation; 2002.

40 Nandy S, Irving M, Gordon D, Subramanian SV, Smith GD. Poverty, child undernutrition and morbidity: new evidence from India. Bull World Health Organ. 2005;83:210-6. Medline:15798845

41 Svedberg P. Poverty and undernutrition: theory, measurement and policy. New Delhi: Oxford India Paperbacks; 2000.

42 Rosenbloom JI, Kaluski DN, Berry EM. A global nutritional index. Food Nutr Bull. 2008;29:266-77. Medline:19227051 doi:10.1177/156482650802900403

43 Eslava-Schmalbach J, Alfonso H, Oliveros H, Gaitan H, Agudelo C. A new Inequity-in-Health Index based on Millennium Development Goals: methodology and validation. J Clin Epidemiol. 2008;61:142-50. Medline:18177787 doi:10.1016/j. jclinepi.2007.05.001

44 Peppard PE, Kindig DA, Dranger E, Jovaag A, Remington PL. Ranking community health status to stimulate discussion of local public health issues: the Wisconsin County Health Rankings. Am J Public Health. 2008;98:209-12. Medline:18172156 doi:10.2105/AJPH.2006.092981

45 Sartorius BK, Sartorius K. A new multidimensional population health indicator for policy makers: absolute level, inequality and spatial clustering - an empirical application using global sub-national infant mortality data. Geospat Health. 2014;9:7-26. Medline:25545922 doi:10.4081/gh.2014.2

46 Health outcomes and cost: A 166-country comparison. The Economist Intelligence Unit, Healthcare TEIU; 2014.

47 Tan H, Ng C, Ho C, Teo C. Asian men's health report. Kuala Lumpur: Malaysian Men's Health Initiative. 2013.

48 McEvoy R, Richardson N, editors. Men's health in Ireland. Men's Health Forum in Ireland. 2004. Available: http://www. mhfi.org/fullreport.pdf. Accessed: 1 November 2018.

49 Nilsen P. Making sense of implementation theories, models and frameworks. Implement Sci. 2015;10:53. Medline:25895742 doi:10.1186/s13012-015-0242-0

50 Grant MJ, Booth A. A typology of reviews: an analysis of 14 review types and associated methodologies. Health Info Libr J. 2009;26:91-108. Medline:19490148 doi:10.1111/j.1471-1842.2009.00848.x 